\title{
Cyanide degradation by Pseudomonas pseudoalcaligenes CECT5344 involves a malate : quinone oxidoreductase and an associated cyanide-insensitive electron transfer chain
}

\begin{abstract}
Correspondence
M. Dolores Roldán

bb2rorum@uco.es
\end{abstract}

Received 7 September 2010

Revised 20 December 2010

Accepted 22 December 2010

\author{
Victor M. Luque-Almagro, ${ }^{1} \dagger$ Faustino Merchán, ${ }^{2 \dagger}$ Rafael Blasco, ${ }^{2}$ \\ M. Isabel Igeño, ${ }^{2}$ Manuel Martínez-Luque, ${ }^{1}$ Conrado Moreno-Vivián, ${ }^{1}$ \\ Francisco Castillo ${ }^{1}$ and M. Dolores Roldán ${ }^{1}$
${ }^{1}$ Departamento de Bioquímica y Biología Molecular, Campus de Rabanales, Edificio Severo Ochoa, $1^{\text {a }}$ Planta, Universidad de Córdoba, Córdoba, Spain
${ }^{2}$ Departamento de Bioquímica y Biología Molecular y Genética, Facultad de Veterinaria, Universidad de Extremadura, Cáceres, Spain

The alkaliphilic bacterium Pseudomonas pseudoalcaligenes CECT5344 is able to grow with cyanide as the sole nitrogen source. Membrane fractions from cells grown under cyanotrophic conditions catalysed the production of oxaloacetate from L-malate. Several enzymic activities of the tricarboxylic acid and glyoxylate cycles in association with the cyanide-insensitive respiratory pathway seem to be responsible for the oxaloacetate formation in vivo. Thus, in cyanide-grown cells, citrate synthase and isocitrate lyase activities were significantly higher than those observed with other nitrogen sources. Malate dehydrogenase activity was undetectable, but a malate: quinone oxidoreductase activity coupled to the cyanide-insensitive alternative oxidase was found in membrane fractions from cyanide-grown cells. Therefore, oxaloacetate production was linked to the cyanide-insensitive respiration in P. pseudoalcaligenes CECT5344. Cyanide and oxaloacetate reacted chemically inside the cells to produce a cyanohydrin (2-hydroxynitrile), which was further converted to ammonium. In addition to cyanide, strain CECT5344 was able to grow with several cyano derivatives, such as 2- and 3-hydroxynitriles. The specific system required for uptake and metabolization of cyanohydrins was induced by cyanide and by 2-hydroxynitriles, such as the cyanohydrins of oxaloacetate and 2-oxoglutarate.

\section{INTRODUCTION}

Cyanide can be found in nature in many different forms due to the chemical properties of the cyano group $(-\mathrm{C} \equiv \mathrm{N})$. Free cyanide corresponds to the $\mathrm{CN}^{-}$ion in solution or cyanhydric acid gas, depending on the $\mathrm{pH}\left(\mathrm{p} K_{\mathrm{a}}\right.$ 9.2). Nitriles $(\mathrm{R}-\mathrm{C} \equiv \mathrm{N})$ are organic cyanides widely distributed in the biosphere. Cyanide may be generated as a natural compound by some bacteria, algae, fungi and higher plants, and even by insects, mainly for defensive or offensive purposes (Dubey \& Holmes, 1995; Pessi \& Haas, 2004; Zagrobelny et al., 2008). However, environmental problems

†These authors contributed equally to this work.

Abbreviations: AOX, cytochrome bd-type alternative oxidase; DCPIP, dichlorophenolindophenol; MQO, malate: quinone oxidoreductase; MSX, L-methionine-DL-sulfoximine; OAA-CN, cyanohydrin of oxaloacetate; 2OG-CN, cyanohydrin of 2-oxoglutarate.

A supplementary figure, showing HPLC detection of the 2-hydroxynitrile transiently released to the medium by $P$. pseudoalcaligenes CET5344 cells grown with cyanide, is available with the online version of this paper. caused by cyanide are due to the production of large amounts of cyanide-containing wastes by human industrial activities, such as production of organic nitriles, nylon and acrylic plastics, paints, dyes, drugs, chelating agents, etc., and the use of cyanide in gold mining and the metal and jewellery industries. Chemical treatments to remove cyanide are very expensive and generate products that are also toxic, so that cyanide biodegradation may be an attractive alternative treatment (Raybuck, 1992; Dubey \& Holmes, 1995; Akcil \& Mudder, 2003; Ebbs, 2004). Cyanide is highly toxic to most living organisms, as it binds strongly to metalloproteins (Solomonson, 1981). In spite of its toxicity, different cyanide degradation pathways based on hydrolytic, oxidative and substitution/addition reactions have been described in some micro-organisms (Dubey \& Holmes, 1995; Huertas et al., 2006; Gupta et al., 2010). Most cyanotrophic organisms operate at neutral $\mathrm{pH}$, and consequently cyanide evaporates as cyanhydric acid. The hydrolysis of cyanide produces formic acid and ammonium (Kunz et al., 2001). The oxidative degradation of cyanide 
occurs either in a single step or in two steps (with the formation of cyanate) with $\mathrm{CO}_{2}$ and $\mathrm{NH}_{4}^{+}$production (Ebbs, 2004). The substitution/addition reactions produce either thiocyanate (Dubey \& Holmes, 1995) or 3-cyanoalanine (Blumenthal et al., 1968; Castric \& Strobel, 1969). A mechanism of cyanide degradation including release of 2oxoglutarate and pyruvate to the medium, and formation of their cyanohydrins via a cyanide oxygenase, has been proposed for Pseudomonas fluorescens NCIMB 11764 (Kunz et al., 1998). However, the accumulation of 2oxoacids in the medium was later demonstrated to be a nonspecific mechanism associated with nitrogen-limiting conditions (Fernández \& Kunz, 2005). Cyanohydrins are putative substrates for nitrilases or nitrile hydratases (Gerasimova et al., 2004; Podar et al., 2005). Degradation of these nitriles can be achieved either in a single step by a nitrilase or in two steps catalysed by a nitrile hydratase/ amidase system, and both generate ammonium (O'Reilly \& Turner, 2003; Gerasimova et al., 2004).

An alkaliphilic bacterial strain able to degrade cyanide was isolated from sludges of the Guadalquivir River (Córdoba, Spain). This bacterium, identified as Pseudomonas pseudoalcaligenes CECT5344, grows at an optimum $\mathrm{pH}$ of 9.5 and uses $2 \mathrm{mM}$ cyanide as the sole nitrogen source (Luque-Almagro et al., 2005a, b; Huertas et al., 2010). This strain can also use cyano-metal complexes, cyanate and the residue from the jewellery industry as the sole nitrogen source (Luque-Almagro et al., 2005a, b, 2008). In this bacterium, a cyanide-insensitive respiration system has been described, which includes a cytochrome $b d$-type alternative oxidase (AOX) that replaces the cytochrome $c$ oxidase (Quesada et al., 2007). In this work we describe for what is believed to be the first time that a malate: quinone oxidoreductase (MQO) activity associated with the cyanide-insensitive alternative oxidase is present as a malate oxidase system in cyanide-grown cells. The MQO enzyme produces oxaloacetate from malate, which spontaneously reacts with free cyanide to generate its corresponding cyanohydrin, which is further converted into ammonium.

\section{METHODS}

Culture conditions. $P$. pseudoalcaligenes CECT5344 was isolated from the Guadalquivir River (Córdoba, Spain) by using enrichment techniques (Luque-Almagro et al., 2005a). The bacterium was cultured at pH 9.5 in M9 minimal medium (Sambrook et al., 1989) without citrate and with $50 \mathrm{mM}$ sodium acetate as carbon source. Ammonium, cyanide, 3-cyanoalanine or the cyanohydrins of oxaloacetate (OAA-CN) and 2-oxoglutarate (2OG-CN) were used as nitrogen source at $2 \mathrm{mM}$ final concentration. Cultures were incubated in a shaker at 250 r.p.m. and $30{ }^{\circ} \mathrm{C}$. Resting cells were prepared by inoculation of strain CECT5344 into M9 medium containing cyanide, ammonium or OAA-CN (2 mM final concentration) as the sole nitrogen source. At the middle of the exponential growth phase $\left(\mathrm{OD}_{600} 0.4\right)$, cells were harvested, resuspended in $50 \mathrm{mM}$ Tris/ $\mathrm{HCl}(\mathrm{pH} 8.0)$ and concentrated to $\mathrm{OD}_{600} 1.0$, and $2 \mathrm{mM}$ OAA-CN and $100 \mu \mathrm{M}$ L-methionine-DL-sulfoximine (MSX), an inhibitor of glutamine synthetase, were also added.
In vitro synthesis of cyanohydrins. Cyanohydrins are not always commercially available, so their synthesis was carried out in an optimized chemical process. Different $\mathrm{CN}^{-} / 2$-oxoacid ratios were tested, and the highest formation of cyanohydrin was achieved with a $\mathrm{CN}^{-} / 2$-oxoacid ratio of $5: 80$. The $\mathrm{pH}$ dependency of the synthesis of cyanohydrins was another parameter considered. In the case of 2OG$\mathrm{CN}$, synthesis was favoured at alkaline $\mathrm{pH}$, although the synthesis of OAA-CN was successfully achieved in a wide $\mathrm{pH}$ range of 6.5-9.5. The synthesis was carried out at room temperature in a shaker at 20 r.p.m.; in all cases, chemical reactions developed very fast, and after 15 min of incubation, free cyanide was almost undetectable at the optimal $\mathrm{pH}$ values. After this period of time, $98-99 \%$ of the initial cyanide concentration $(5 \mathrm{mM})$ remained in the controls performed without addition of the corresponding 2-oxoacid.

Analytical determinations. Bacterial growth was monitored by following $\mathrm{OD}_{600}$. Ammonium concentration was determined using Nessler reagent, as described by Morrison (1971). Free cyanide concentration was determined colorimetrically (Asmus \& Garschagen, 1953). Protein concentration was estimated by the method of Bradford (1976). 2-Oxoacid concentration was determined at $520 \mathrm{~nm}$ in the presence of 2,4-dinitrophenylhydrazine (Borchers, 1977). Oxaloacetate, 2-oxoglutarate and their respective cyanohydrins were determined by HPLC in a System Gold (Beckman) with diode array and with an Aminex HPX-87H anionic exchange column (Bio$\mathrm{Rad})$, monitoring $A_{210}$ with an isocratic gradient in the presence of $8 \mathrm{mM} \mathrm{H}_{2} \mathrm{SO}_{4}$ and at a flow rate of $0.5 \mathrm{ml} \mathrm{min}^{-1}$. Oxaloacetate was also determined using purified malate dehydrogenase, as described below.

Preparation of cell-free extracts and determination of enzymic activities. Cell-free extracts were prepared from cells grown with the indicated nitrogen sources ( $2 \mathrm{mM}$ final concentration) required for each experiment. Cells were harvested at the latest stage of the exponential growth phase and resuspended in $50 \mathrm{mM}$ Tris/ $\mathrm{HCl}$ buffer $(\mathrm{pH} 8.0)$. Cells were broken in a French press at 16000 p.s.i. $(110 \mathrm{MPa})$. After centrifugation at $10000 \mathrm{~g}$ for $30 \mathrm{~min}$ to remove whole cells and cell debris, the supernatant was ultracentrifuged at $68000 \mathrm{~g}$ for $90 \mathrm{~min}$. Supernatants were collected and used as the source of soluble enzymes, and the pellet corresponding to the membrane fractions was washed twice in $50 \mathrm{mM}$ Tris/HCl buffer ( $\mathrm{pH}$ 8.0). To check the purity of the membrane fractions, fumarase activity was determined, and this enzymic activity was never detected in these fractions. In addition, MQO activity could not be detected in the soluble fraction (cytoplasm and periplasm) under the experimental conditions tested. Determination of free cyanide and OAA$\mathrm{CN}$ was as described above in the different soluble subcellular fractions. For this purpose, 1.51 of cells cultured with $2 \mathrm{mM}$ cyanide as the sole nitrogen source was harvested when more than $1 \mathrm{mM}$ cyanide was consumed and $200 \mu \mathrm{M}$ nitrile detected in the supernatant. Cells were harvested by centrifugation and disrupted by incubation in SET buffer [0.5 M sucrose, $20 \mathrm{mM}$ EDTA, $75 \mathrm{mM}$ Tris/ $\mathrm{HCl}$ ( $\mathrm{pH} 8.0), 0.2 \mathrm{mg}$ lysozyme $\mathrm{ml}^{-1}$ ] for $30 \mathrm{~min}$ at $30{ }^{\circ} \mathrm{C}$. After a centrifugation at $10000 \mathrm{~g}$, the supernatant, corresponding to the periplasmic fraction, was kept at $4{ }^{\circ} \mathrm{C}$ for further analysis. The pellet, corresponding to the spheroplasts, was resuspended in $50 \mathrm{mM}$ Tris/ $\mathrm{HCl}(\mathrm{pH} 8.0)$ and spheroplasts were disrupted by cavitation, three pulses of $5 \mathrm{~min}$ at $90 \mathrm{~W}$, followed by a centrifugation step at $19000 \mathrm{~g}$. Then, the supernatant, corresponding to the cytoplasmic fraction, was kept at $4{ }^{\circ} \mathrm{C}$ for further analysis. Before HPLC analysis, the subcellular soluble fractions were deproteinized by filtration in a $5 \mathrm{kDa}$ cut-off centrifugal filter.

Fumarase activity was determined spectrophotometrically at $240 \mathrm{~nm}$ as described previously (Martínez Luque-Romero \& Castillo, 1991). Aconitase was assayed by following the increase in $A_{240}$ in the presence of citrate (Martínez Luque-Romero \& Castillo, 1991). Malate 
dehydrogenase and isocitrate dehydrogenase activities were determined spectrophotometrically at $340 \mathrm{~nm}$ according to Smith (1983) and Goldberg \& Ellis (1983), respectively. Isocitrate lyase was assayed in $50 \mathrm{mM}$ MOPS buffer ( $\mathrm{pH} 7.5$ ) containing $5 \mathrm{mM} \mathrm{MgCl} 2,1 \mathrm{mM}$ isocitrate, $1 \mathrm{mM}$ DTT and $1 \%$ phenylhydrazine. The reaction was stopped by the addition of $0.5 \mathrm{ml} 12 \mathrm{M} \mathrm{HCl}$, and $0.25 \%$ ferricyanide was added to develop a yellow colour at $520 \mathrm{~nm}$ (Díaz-Pérez et al., 2007). Citrate synthase was determined as described by Eidels \& Preiss (1970) in $0.1 \mathrm{M}$ Tris/HCl buffer ( $\mathrm{pH} 8.0$ ) containing $1 \mathrm{mM}$ oxaloa-

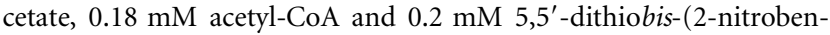
zoic acid). Malate oxidase activity was determined by following either the disappearance of oxygen in a Clark-type electrode (Oxygraph system, Hansatech) or malate consumption by HPLC as described above for 2-oxoacids. The reaction mixture contained, in a $1 \mathrm{ml}$ final volume, $50 \mathrm{mM}$ Tris/ $\mathrm{HCl}$ buffer $(\mathrm{pH} 8.0), 5 \mathrm{mM} \mathrm{L}$-malate and the appropriate amount of membrane fraction. The assays were carried out at $30{ }^{\circ} \mathrm{C}$ and were started by the addition of L-malate. The MQO activity was measured as described by Molenaar et al. (1998). The reaction mixture contained, in a $1 \mathrm{ml}$ final volume, $50 \mathrm{mM}$ Tris/ $\mathrm{HCl}$ buffer ( $\mathrm{pH} 8.0$ ), $0.05 \mathrm{mM}$ dichlorophenolindophenol (DCPIP) and $2 \mathrm{mM}$ L-malate. The activity was determined by DCPIP reduction followed at $600 \mathrm{~nm}$. The specific activity was calculated assuming a molar extinction coefficient for DCPIP of $22 \mathrm{mM}^{-1} \mathrm{~cm}^{-1}$.

\section{RESULTS}

\section{Effect of cyanide on several enzymes of the tricarboxylic acid (TCA) and glyoxylate cycles}

$P$. pseudoalcaligenes CECT5344 is able to grow with $2 \mathrm{mM}$ cyanide as the sole nitrogen source. To analyse the putative effect of cyanide on enzymes from central metabolic pathways, different enzymic activities from the TCA and glyoxylate cycles were determined in cell-free extracts from cyanide-, ammonium- or nitrate-grown cells, and from cells grown under nitrogen-limiting conditions. In the presence of cyanide, citrate synthase and isocitrate lyase activities were about two- and fivefold higher, respectively, than in media with ammonium, and about two- and 25fold higher, respectively, than in nitrate-grown cells (Table 1). However, aconitase activity was lower with cyanide than with the other nitrogen sources tested, probably because cyanide binds to the metal cofactor of this enzyme. Fumarase activity in cyanide-grown cells was also lower than that observed in cells grown with ammonium or nitrate, but similar to that found under nitrogen-starvation conditions. Other enzymic activities from the Krebs and glyoxylate cycles were similar in media with cyanide or ammonium (not shown).

\section{P. pseudoalcaligenes CECT5344 lacks malate dehydrogenase but has an MQO as a component of the respiratory electron transfer system}

Malate dehydrogenase activity was not detected in any of the subcellular fractions or growth conditions tested (Table 1), suggesting that in strain CECT5344, MQO may replace the malate dehydrogenase.

The MQO activity was measured in membrane fractions either spectrophotometrically, with DCPIP as artificial oxidant, or in an assay coupled to the terminal oxidase (with oxygen as terminal electron acceptor), following Lmalate consumption by HPLC and oxygen uptake with a Clark electrode. This coupled assay can be considered as the malate oxidase system, which was present with all nitrogen sources tested and was not specifically induced in cyanide-grown cells (Table 1). However, addition of cyanide to the in vitro malate oxidase assays caused inhibition of the activity, except when membrane fractions from cyanide-grown cells were used (not shown). The MQO activity determined with DCPIP as artificial oxidant was proportional to the malate oxidase activity in the presence of all nitrogen sources (not shown), suggesting that MQO is coupled to AOX under cyanotrophic conditions and to cytochrome $c$ oxidase in the absence of cyanide (Fig. 1). Accordingly, in vitro experiments carried out with different subcellular fractions showed that in the presence of malate, the cyanide concentration decreased when membrane fractions from cyanide-grown cells were used (Fig. 2). Cyanide was only consumed when oxaloacetate was produced as a consequence of MQO activity

Table 1. Enzymic activities affected by cyanide in P. pseudoalcaligenes CECT5344

Specific activity values are shown $\left[\mathrm{nmol} \mathrm{min}^{-1}(\mathrm{mg} \text { protein })^{-1}\right.$. Values are mean \pm SD from four independent determinations. ND, Not detected.

\begin{tabular}{|lcccc|}
\hline & $\mathrm{NH}_{4}^{+}$ & $\mathrm{NO}_{3}^{-}$ & $-\mathbf{N} \boldsymbol{}$ & $\mathbf{C N}^{-}$ \\
\hline Enzymic activity & & & & \\
\hline Isocitrate lyase & $71 \pm 5$ & $13 \pm 1$ & $16 \pm 1$ & $329 \pm 12$ \\
Citrate synthase & $174 \pm 10$ & $182 \pm 5$ & $10 \pm 1$ & $339 \pm 10$ \\
Aconitase & $163 \pm 9$ & $152 \pm 2$ & $105 \pm 2$ & $39 \pm 2$ \\
Fumarase & $2500 \pm 20$ & $2622 \pm 16$ & $820 \pm 6$ & $730 \pm 4$ \\
Malate dehydrogenase & $\mathrm{ND}$ & $\mathrm{ND}$ & $\mathrm{ND}$ & $\mathrm{ND}$ \\
Malate oxidase* & $74 \pm 3$ & $64 \pm 3$ & $25 \pm 1$ & $31 \pm 1$ \\
\hline
\end{tabular}

*The malate oxidase system is responsible for the $\mathrm{O}_{2}$-dependent synthesis of oxaloacetate from malate, and includes MQO coupled to the terminal oxidase (AOX in cyanide-grown cells or cytochrome $c$ oxidase in cells growing without cyanide).

$\dagger$ Nitrogen starvation. 


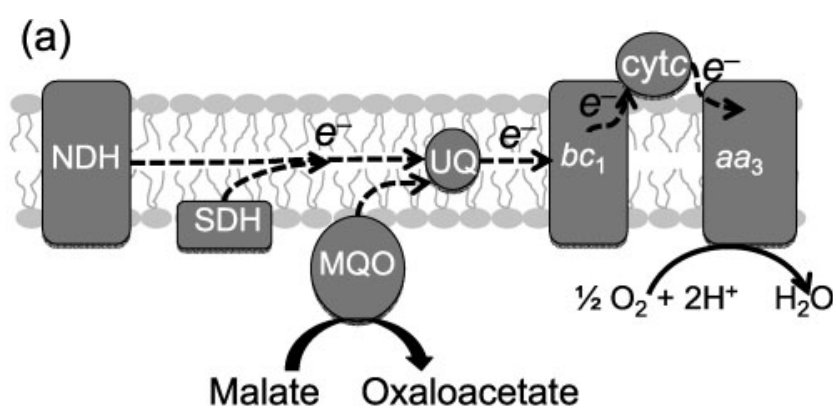

(b)

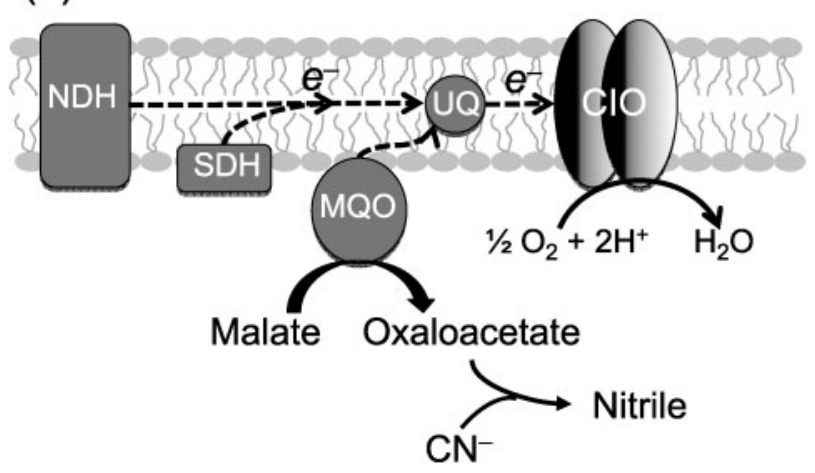

Fig. 1. Components of the electron transfer chain in $P$. pseudoalcaligenes CECT5344 cells grown without (a) or with (b) cyanide. The cyanide degradation process includes an early response by which oxaloacetate is produced as a consequence of the stimulation of the glyoxylate cycle and the cyanide-insensitive respiratory system. Abbreviations: $\mathrm{ClO}$, cyanide-insensitive oxidase; $\mathrm{NDH}, \mathrm{NADH}$ : ubiquinone oxidoreductase (complex I); $\mathrm{SDH}$, succinate dehydrogenase; UQ, ubiquinol/ubiquinone pool. For simplicity, proton translocation coupled to the electron transport chain has been omitted.

during aerobic respiration in the presence of cyanide. Oxaloacetate and cyanide react chemically to form a nitrile. In contrast, cyanide was not consumed in assays with membrane fractions from cells grown with other nitrogen sources, such as nitrate and ammonium (Fig. 2). These results suggest that the $\mathrm{MQO}$ activity responsible for oxalacetate formation is probably coupled to the cyanideinsensitive $\mathrm{AOX}$ encoded by the $\operatorname{cio} A B$ genes, which is detected in cyanide-grown cells (Quesada et al., 2007; Fig. 1).

\section{A nitrile is transiently accumulated in cyanide- containing media}

Degradation of cyanide by P. pseudoalcaligenes CECT5344 occurs through production of ammonium, which is further assimilated by glutamine synthetase (Luque-Almagro et al., 2005a, 2007). To test whether oxaloacetate or other 2oxoacids and/or their related nitriles were released to cyanide-containing media, cells were grown in M9 minimal medium containing $50 \mathrm{mM}$ acetate as a carbon source and

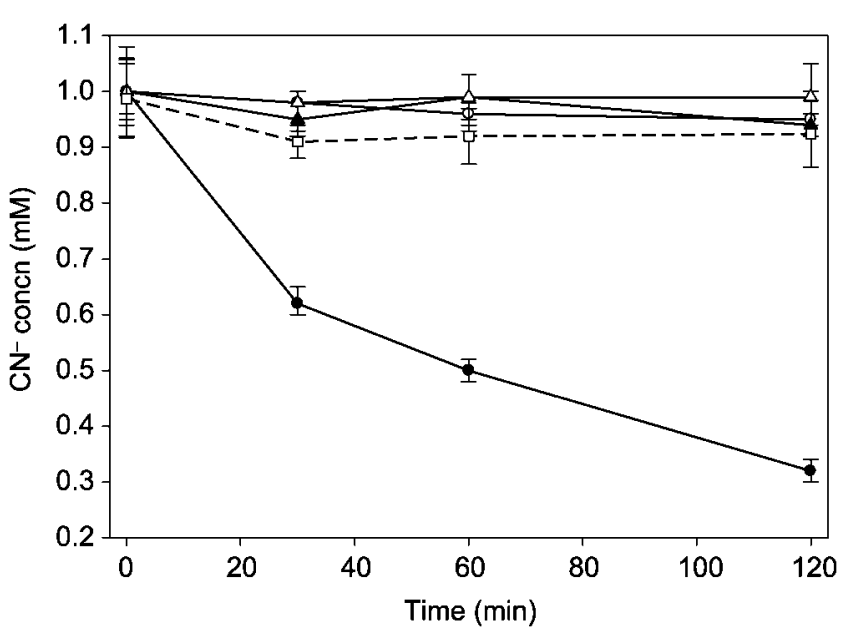

Fig. 2. In vitro cyanide consumption by membrane fractions of $P$. pseudoalcaligenes CECT5344. Cyanide consumption was determined in assays carried out with $5 \mathrm{mM}$ L-malate and membrane fractions from cells grown with cyanide $(\bullet)$, ammonium $(\bigcirc)$ or nitrate $(\boldsymbol{\Delta})$. An assay with the soluble (cytoplasm and periplasm) subcellular fraction was also carried out (dashed line, $\square$ ). In addition, a control without subcellular fractions was performed $(\triangle)$.

$2 \mathrm{mM}$ ammonium chloride for $24 \mathrm{~h}$, until nitrogen was completely depleted. Then, cells were harvested by centrifugation and resuspended in fresh minimal medium containing cyanide, nitrate or ammonium $(2 \mathrm{mM}$ final concentration) as nitrogen source. The production of 2oxoacids by $P$. pseudoalcaligenes CECT5344 was spectrophotometrically determined in all these cultures. In addition, cyanide uptake and bacterial growth were determined in media containing this compound (Fig. 3). 2-Oxoacids were undetectable by HPLC in supernatants from cyanide-containing media, and only a peak that may correspond to OAA-CN (a 2-hydroxynitrile) was observed (Supplementary Fig. S1). However, the spectrophotometric analysis of these supernatants revealed the presence of putative 2-oxoacids. Oxaloacetate was used as a standard, and after injection into the HPLC system showed a different retention time to that shown by the nitrile. Also, assays carried out with purified malate dehydrogenase revealed that oxaloacetate was not present. This could be explained by the fact that, as mentioned above, 2oxoacids spontaneously react with cyanide to form cyanohydrins. The compound was partially purified by HPLC from supernatants and added to fresh minimal M9 medium as the sole nitrogen source. Cells were able to grow in the presence of this compound, as shown in Fig. 4 (a). To provide a standard, in vitro synthesis of OAA-CN was carried out using a mixture of oxaloacetate and sodium cyanide in buffer solution, as described in Methods. The growth of strain CECT5344 was also followed in the presence of this standard as the sole nitrogen source and compared with that in the presence of the compound purified from media containing cyanide 


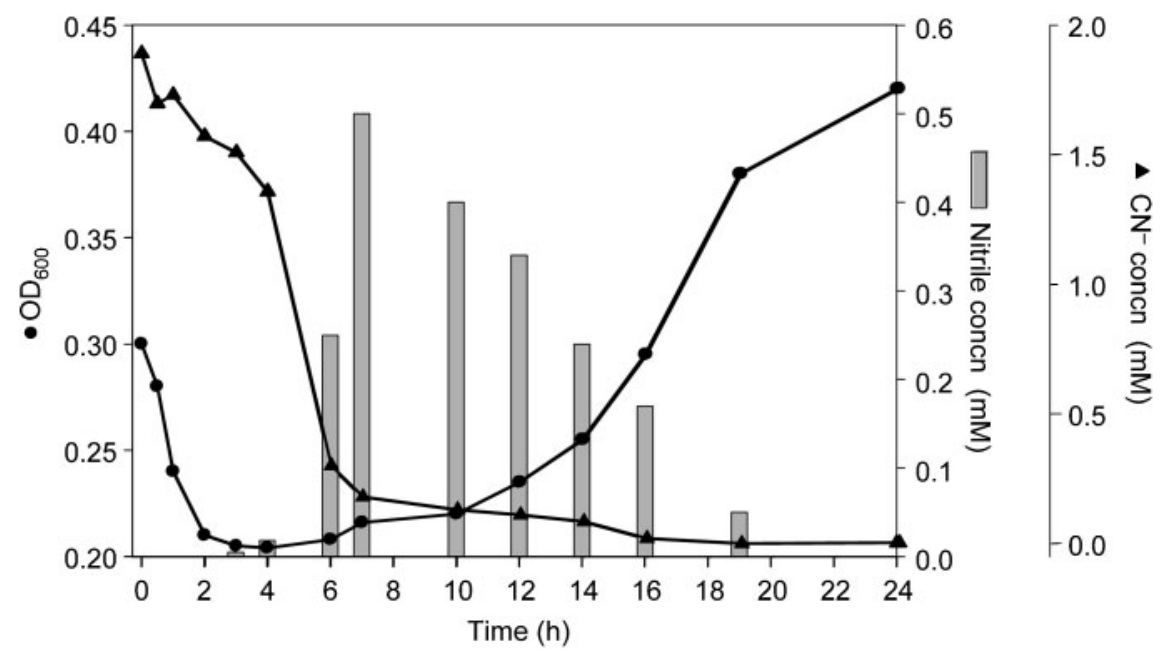

Fig. 3. Bacterial growth, and cyanide uptake and nitrile accumulation by $P$. pseudoalcaligenes CECT5344. Cells were grown with $2 \mathrm{mM}$ ammonium chloride for $24 \mathrm{~h}$, harvested and resuspended in fresh medium with cyanide as the sole nitrogen source ( $2 \mathrm{mM}$ final concentration). Bacterial growth $(\mathbf{0})$ was monitored by $\mathrm{OD}_{600}$. The presence of nitriles (grey bars) was analysed by HPLC. Cyanide uptake $(\boldsymbol{\Delta})$ was followed spectrophotometrically at $578 \mathrm{~nm}$. Data correspond to a representative experiment that was repeated four times, yielding essentially the same results.

(Fig. 4a). Medium containing ammonium was used as a control in this experiment.

Free cyanide and the nitrile were measured in subcellular fractions from cyanide-grown cells, and small amounts of cyanide (in the $\mu \mathrm{M}$ range) were detected in the subcellular cytoplasmic fraction of $P$. pseudoalcaligenes CECT5344 cells. Nitrile detection in subcellular fractions was carried out by HPLC, as described in Methods, and, in addition to its detection in supernatants of cyanide-grown cells, the compound was also detected in the cytoplasmic fraction, although it was absent from periplasmic fractions from cyanide-grown cells. Oxaloacetate production was not observed when the cyanide-grown cells were incubated with acetate as carbon source with no added nitrogen. However, small amounts of oxaloacetate were detected in the presence of L-malate.

\section{Degradation of OAA-CN is induced by cyanide and occurs through ammonium formation}

Cells grown with ammonium, cyanide, 3-cyanoalanine, 2OG-CN or OAA-CN as the sole nitrogen source were harvested by centrifugation after $24 \mathrm{~h}$ growth and resuspended in fresh minimal medium with OAA-CN as the sole nitrogen source, and bacterial growth was monitored by following $\mathrm{OD}_{600}$ (Fig. 4b). Cultures previously induced with cyanide or with OAA-CN or 2OG-CN did not show a lag phase compared with those precultured with 3-cyanoalanine (a 3-hydroxynitrile) or ammonium. Additionally, the growth rates of cells pre-cultured with 3-cyanoalanine or ammonium were lower (doubling time of $4.3 \pm 0.5 \mathrm{~h}$ ) than those precultured with cyanide or 2-hydroxynitriles (doubling time of $3 \pm 0.4 \mathrm{~h}$ ), probably because the OAA-CN degradation system was not induced in cells cultured with these nitrogen sources (Fig. 4b). The OAA-CN was metabolized by $P$. pseudoalcaligenes CECT5344 through ammonium formation, as revealed by the accumulation of ammonium when the glutamine synthetase activity of resting cells pre-cultured with $\mathrm{OAA}-\mathrm{CN}$ was inhibited by MSX, an inhibitor of glutamine synthetase (Fig. 5a). Ammonium accumulation was also observed when the cells pre-cultured with cyanide were incubated with OAA-CN in the presence of MSX. However, in cells pre-cultured with ammonium, the OAA-CN degradation system, which includes a system to transport the cyanohydrin inside the cell and also a degradation/assimilation pathway, was not induced, since ammonium did not accumulate in the presence of MSX (Fig. 5a).

On the other hand, the presence of additional nitrogen sources such as ammonium and nitrate in the cyanidecontaining media did not affect the formation and accumulation of OAA-CN and the subsequent cyanohydrin metabolization, as demonstrated by the generation of ammonium from OAA-CN in the presence of nitrate or ammonium after MSX treatment (Fig. 5b). However, ammonium was never detected in controls treated with MSX in the presence of these alternative nitrogen sources but in the absence of OAA-CN (not shown).

\section{DISCUSSION}

The presence of cyanide causes changes in several enzymic activities of the Krebs and glyoxylate cycles in the cyanotrophic bacterium P. pseudoalcaligenes CECT5344. Thus, citrate synthase and isocitrate lyase are highly 

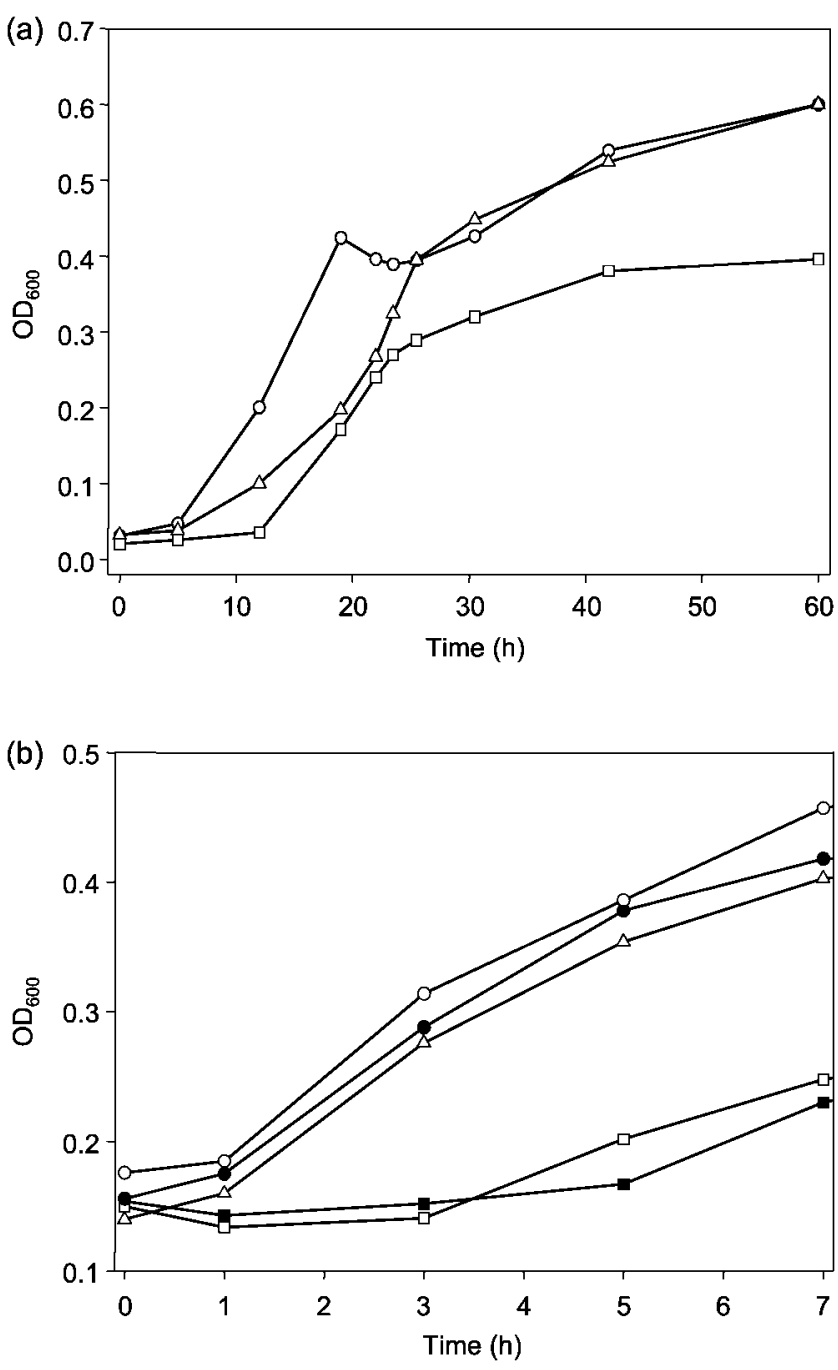

Fig. 4. Growth of $P$. pseudoalcaligenes CECT5344 with several nitriles as the sole nitrogen source. Induction of OAA-CN assimilation by cyanide and cyanohydrins. (a) Cells were cultured in $\mathrm{M} 9$ minimal medium with $50 \mathrm{mM}$ acetate as carbon source and the nitrogenous compound isolated from cyanide-containing media $(\triangle), 2 \mathrm{OG}-\mathrm{CN}(\bigcirc)$ or OAA-CN $(\square)$ at $2 \mathrm{mM}$ final concentration as the sole nitrogen source. Bacterial growth was measured by following $\mathrm{OD}_{600}$. Data correspond to a representative experiment that was repeated three times, yielding essentially the same result. (b) Cells were grown with several nitrogen sources (2 $\mathrm{mM}$ final concentration): ammonium chloride ( $\square)$, 3-cyanoalanine ( $\square$ ), cyanide $(\triangle)$, OAA-CN $(\bullet)$ or 2OG-CN $(\bigcirc)$. After $24 \mathrm{~h}$, cells were centrifuged and resuspended in fresh $\mathrm{M} 9$ minimal medium with $\mathrm{OAA}-\mathrm{CN}$ as the sole nitrogen source, and bacterial growth was determined by following $\mathrm{OD}_{600}$. Data correspond to a representative experiment that was repeated three times, yielding essentially the same result.

stimulated in cyanide-induced cells (Table 1). A similar mechanism has been described for aluminium detoxification in P. fluorescens, which overexpresses isocitrate lyase to produce succinate and glyoxylate, which is further converted
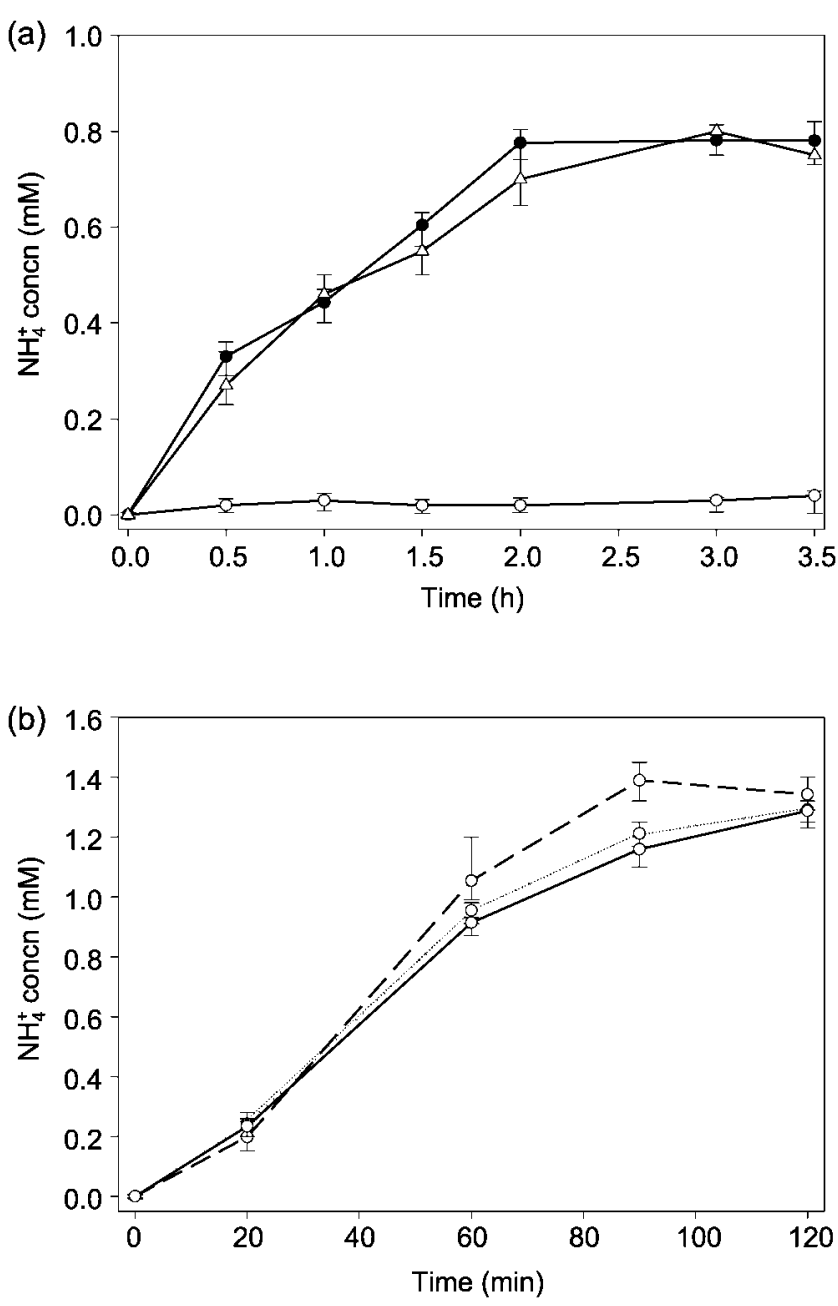

Fig. 5. Ammonium formation during $\mathrm{OAA}-\mathrm{CN}$ assimilation in $P$. pseudoalcaligenes CECT5344. (a) Resting cells were prepared as indicated in Methods from cells grown with ammonium ( $\bigcirc$ ), cyanide $(\triangle)$ or OAA-CN $(\bullet)$. MSX, an inhibitor of glutamine synthetase, was also added to the resting cells at $100 \mu \mathrm{M}$ final concentration (time 0 in the experiment). (b) Assimilation of OAA$\mathrm{CN}$ in the presence of several nitrogen sources. After $100 \mu \mathrm{M}$ MSX addition (time 0 in the experiment), ammonium generated from OAA-CN assimilation was determined in supernatants of resting cells with $2 \mathrm{mM}$ OAA-CN in the presence of nitrate (dotted line) or ammonium (dashed line) as additional nitrogen sources (4 $\mathrm{mM}$ final concentration) and in a control without an additional nitrogen source (solid line).

into oxalate, which binds aluminium (Hamel et al., 2004). On the other hand, in cyanide-grown cells, a decrease of the aconitase and fumarase activities can also be expected, because it is known that cyanide binds to metals and causes inhibition of metalloenzymes. In $P$. pseudoalcaligenes CECT5344, cyanide induces a cyanide-insensitive respiratory chain with malate oxidase activity. The malate oxidase system has at least two components, the MQO and the cyanide-insensitive AOX (Fig. 1). Curiously, malate dehydrogenase activity could not be detected in this strain with 
any of the nitrogen sources tested (Table 1). It has been reported that Helicobacter pylori has an unusual type of citric acid cycle that uses the membrane-located MQO activity to replace malate dehydrogenase activity (Kather et al., 2000). Also, the MQO enzyme has been described to be essential for growth on ethanol and acetate in Pseudomonas aeruginosa (Kretzschmar et al., 2002). When the MQO activity was determined in strain CECT5344, it was found that this activity was coupled to the terminal oxidase and replaced the malate dehydrogenase with all nitrogen sources tested (Table 1). Therefore, the malate oxidase system in cyanide-grown cells is composed of the MQO and AOX activities, which are required for cyanide-insensitive respiration and are induced by cyanide (Quesada et al., 2007). However, in nitrate- or ammonium-grown cells, the MQO activity is coupled to the cytochrome $c$ oxidase, and this malate oxidase system is cyanide-sensitive. Membrane preparations only consumed cyanide when they were isolated from cyanide-grown cells (Fig. 2), suggesting that strain CECT4344 forms oxaloacetate in response to cyanide by stimulation of the glyoxylate cycle in association with the MQO and AOX activities required for cyanide-insensitive respiration (Fig. 1). Oxaloacetate production with acetate was not detected in a cyanideinduced cell suspension, although a small amount was produced when L-malate was used as carbon source. Therefore, it can be concluded that under the experimental conditions used (i.e. acetate as carbon source), oxaloacetate is not released to the medium, and that consequently nitrile formation is likely to occur in the cytoplasm.

P. pseudoalcaligenes CECT5344 uses cyanide as a nitrogen source and responds to this compound by defence mechanisms against iron deprivation, oxidative damage and nitrogen stress (Luque-Almagro et al., 2007). This strain also grows in the presence of 2-hydroxynitriles, including OAA-CN, suggesting that this nitrile could act as an intermediate in the cyanide degradation pathway. A compound that may correspond to OAA-CN was found exclusively in cyanide-containing media (Fig. 3). The ability of $P$. pseudoalcaligenes CECT5344 to grow with this nitrogenous compound isolated from cyanide-containing media as the sole nitrogen source (Fig. 4a) indicates that cyanide degradation is initiated by the production of oxaloacetate, which reacts with cyanide to produce its cyanohydrin. It is known that free cyanide reacts chemically with 2-oxoacids to produce nitriles (Kunz et al., 1998). Although a role for 2-oxoglutarate and pyruvate in cyanide assimilation by $P$. fluorescens NCIMB 11764 was initially proposed, a further analysis revealed that cyanide was degraded to formic acid and ammonia (Fernández \& Kunz, 2005). Therefore, the cyanide-induced oxaloacetate formation and transient nitrile accumulation in $P$. pseudoalcaligenes CECT5344 are believed to be the first report of the involvement of 2-oxoacids and nitriles in a cyanide degradation pathway. 2-Oxoacids could not be detected in supernatants from cyanide-containing media by HPLC analysis, although a spectrophotometric determination of 2-oxoacids gave a positive result. Analysis by HPLC of the supernatants from these cultures revealed that only a peak that may correspond to OAA-CN could be observed (Supplementary Fig. S1). This result seems to be contradictory, but can be explained by considering that the samples subjected to 2-oxoacid spectrophotometric detection are heated in the presence of high levels of $\mathrm{NaOH}$, thus causing the non-enzymic formation of free cyanide and the corresponding 2-oxoacid. In addition to the presence of cyanide and the nitrile in supernatants of cyanide-grown cells, free cyanide and the nitrile were also detected in the cytoplasmic fraction of cyanide-grown cells, suggesting that cyanohydrin formation occurs inside the cell. Another fact that demonstrates the presence of cyanide inside the cell is the inhibition of the terminal cytochrome $c$ oxidase (Quesada et al., 2007). Cyanohydrin uptake and degradation are inducible processes, as deduced from the ability of cells pre-cultured with cyanide or cyanohydrins to grow faster with OAA-CN than cells pre-cultured with other nitrogen sources such as ammonium (Fig. 4b). However, a lag phase for growth with OAA-CN was observed in cells pre-cultured with 3-cyanoalanine, suggesting that the degradation pathway for OAA-CN is not induced by 3-cyanoalanine (Fig. 4). The OAA-CN is taken up by the cells through a transport system not yet characterized, and further converted into ammonium via a nitrilase activity or a nitrile hydratase-amidase system. Ammonium is assimilated by glutamine synthetase, as revealed by the accumulation of this nitrogen source in MSX-treated cells (Fig. 5).

In conclusion, in this work we describe the association of a cyanide-insensitive respiration system, which includes the MQO and the cytochrome $b d$ oxidase, with the cyanide degradation/assimilation pathway, and the link between the two processes is oxaloacetate production and OAA-CN formation. This nitrile is further assimilated, probably through a nitrilase or nitrile hydratase-amidase system that generates ammonium, which is incorporated into the carbon skeleton by the glutamine synthetase pathway.

\section{ACKNOWLEDGEMENTS}

This work was funded by Ministerio de Ciencia e Innovación (grants BIO2008-04542-C02-01 and -02, and PET_0048), Junta de Andalucía (grant CVI1728), Junta de Extremadura (grant PRI07A097 and Ayuda a grupos BioMic) and FEDER 2007-2013. V. L.-A. is a recipient of a postdoctoral fellowship from the Ministerio de Ciencia e Innovación, Spain. We also thank GEMASUR, SAVECO and AVENIR for their fruitful collaborations.

\section{REFERENCES}

Akcil, A. \& Mudder, T. (2003). Microbial destruction of cyanide wastes in gold mining: process review. Biotechnol Lett 25, 445-450.

Asmus, E. \& Garschagen, H. (1953). The use of barbituric acid for the photometric determination of cyanide and thiocyanate. $Z$ Anal Chem 138, 414-422.

Blumenthal, S. G., Hendrickson, H. R., Abrol, Y. P. \& Conn, E. E. (1968). Cyanide metabolism in higher plants. 3. The biosynthesis of beta-cyanolanine. J Biol Chem 243, 5302-5307. 
Borchers, R. (1977). Allantoin determination. Anal Biochem 79, 612613.

Bradford, M. M. (1976). A rapid and sensitive method for the quantitation of microgram quantities of protein utilizing the principle of protein-dye binding. Anal Biochem 72, 248-254.

Castric, P. A. \& Strobel, G. A. (1969). Cyanide metabolism by Bacillus megaterium. J Biol Chem 244, 4089-4094.

Díaz-Pérez, A. L., Román-Doval, C., Díaz-Pérez, C., Cervantes, C., Sosa-Aguirre, C. R., López-Meza, J. E. \& Campos-García, J. (2007). Identification of the aceA gene encoding isocitrate lyase required for the growth of Pseudomonas aeruginosa on acetate, acyclic terpenes and leucine. FEMS Microbiol Lett 269, 309-316.

Dubey, S. K. \& Holmes, D. S. (1995). Biological cyanide destruction mediated by microorganisms. World J Microbiol Biotechnol 11, 257-265.

Ebbs, S. (2004). Biological degradation of cyanide compounds. Curr Opin Biotechnol 15, 231-236.

Eidels, L. \& Preiss, J. (1970). Citrate synthase. A regulatory enzyme from Rhodopseudomonas capsulata. J Biol Chem 245, 2937-2945.

Fernández, R. F. \& Kunz, D. A. (2005). Bacterial cyanide oxygenase is a suite of enzymes catalyzing the scavenging and adventitious utilization of cyanide as a nitrogenous growth substrate. $J$ Bacteriol 187, 6396-6402.

Gerasimova, T., Novikov, A., Osswald, S. \& Yanenko, A. (2004). Screening, characterization and application of cyanide-resistant nitrile hydratases. Eng Life Sci 4, 543-546.

Goldberg, D. M. \& Ellis, G. (1983). Isocitrate dehydrogenase. In Methods of Enzymatic Analysis, vol. III, pp. 183-190. Edited by H. U. Bergmeyer, J. Bergmeyer \& M. Grassl. Weinheim: Verlag Chemie.

Gupta, N., Balomajumder, C. \& Agarwal, V. K. (2010). Enzymatic mechanism and biochemistry for cyanide degradation: a review. J Hazard Mater 176, 1-13.

Hamel, R. D., Appanna, V. D., Viswanatha, T. \& Puiseux-Dao, S. (2004). Overexpression of isocitrate lyase is an important strategy in the survival of Pseudomonas fluorescens exposed to aluminum. Biochem Biophys Res Commun 317, 1189-1194.

Huertas, M. J., Luque-Almagro, V. M., Martínez-Luque, M., Blasco, R., Moreno-Vivián, C., Castillo, F. \& Roldán, M. D. (2006). Cyanide metabolism of Pseudomonas pseudoalcaligenes CECT5344: role of siderophores. Biochem Soc Trans 34, 152-155.

Huertas, M. J., Sáez, L. P., Roldán, M. D., Luque-Almagro, V. M., Martínez-Luque, M., Blasco, R., Castillo, F., Moreno-Vivián, C. \& Garcia-García, I. (2010). Alkaline cyanide degradation by Pseudomonas pseudoalcaligenes CECT5344 in a batch reactor. Influence of $\mathrm{pH}$. J Hazard Mater 179, 72-78.

Kather, B., Stingl, K., van der Rest, M. E., Altendorf, K. \& Molenaar, D. (2000). Another unusual type of citric acid cycle enzyme in Helicobacter pylori: the malate:quinone oxidoreductase. J Bacteriol 182, 3204-3209.

Kretzschmar, U., Rückert, A., Jeoung, J.-H. \& Görisch, H. (2002). Malate: quinone oxidoreductase is essential for growth on ethanol or acetate in Pseudomonas aeruginosa. Microbiology 148, 3839-3847.

Kunz, D. A., Chen, J.-L. \& Pan, G. (1998). Accumulation of $\alpha$-keto acids as essential components in cyanide assimilation by Pseudomonas fluorescens NCIMB 11764. Appl Environ Microbiol 64, 4452-4459.

Kunz, D. A., Fernández, R. F. \& Parab, P. (2001). Evidence that bacterial cyanide oxygenase is a pterin-dependent hydroxylase. Biochem Biophys Res Commun 287, 514-518.
Luque-Almagro, V. M., Huertas, M. J., Martínez-Luque, M., Moreno-Vivián, C., Roldán, M. D., García-Gil, L. J., Castillo, F. \& Blasco, R. (2005a). Bacterial degradation of cyanide and its metal complexes under alkaline conditions. Appl Environ Microbiol 71, 940947.

Luque-Almagro, V. M., Blasco, R., Huertas, M. J., Martínez-Luque, M., Moreno-Vivián, C., Castillo, F. \& Roldán, M. D. (2005b). Alkaline cyanide biodegradation by Pseudomonas pseudoalcaligenes CECT5344. Biochem Soc Trans 33, 168-169.

Luque-Almagro, V. M., Huertas, M. J., Roldán, M. D., Moreno-Vivián, C., Martínez-Luque, M., Blasco, R. \& Castillo, F. (2007). The cyanotrophic bacterium Pseudomonas pseudoalcaligenes CECT5344 responds to cyanide by defence mechanisms against iron deprivation, oxidative damage and nitrogen stress. Environ Microbiol 9, 15411549 .

Luque-Almagro, V. M., Huertas, M. J., Sáez, L. P., Luque-Romero, M. M., Moreno-Vivián, C., Castillo, F., Roldán, M. D. \& Blasco, R. (2008). Characterization of the Pseudomonas pseudoalcaligenes CECT5344 cyanase, an enzyme that is not essential for cyanide assimilation. Appl Environ Microbiol 74, 6280-6288.

Martínez Luque-Romero, M. \& Castillo, F. (1991). Inhibition of aconitase and fumarase by nitrogen compounds in Rhodobacter capsulatus. Arch Microbiol 155, 149-152.

Molenaar, D., van der Rest, M. E. \& Petrović, S. (1998). Biochemical and genetic characterization of the membrane-associated malate dehydrogenase (acceptor) from Corynebacterium glutamicum. Eur J Biochem 254, 395-403.

Morrison, G. R. (1971). Microchemical determination of organic nitrogen with Nessler reagent. Anal Biochem 43, 527-532.

O'Reilly, C. \& Turner, P. D. (2003). The nitrilase family of CN hydrolysing enzymes - a comparative study. J Appl Microbiol 95, 1161-1174.

Pessi, G. \& Haas, D. (2004). Cyanogenesis. In Pseudomonas, vol. III, pp. 671-686. Edited by J. L. Ramos. New York: Kluwer Academic/ Plenum Publishers.

Podar, M., Eads, J. R. \& Richardson, T. H. (2005). Evolution of a microbial nitrilase gene family: a comparative and environmental genomics study. BMC Evol Biol 5, 42-54.

Quesada, A., Guijo, M. I., Merchán, F., Blázquez, B., Igeño, M. I. \& Blasco, R. (2007). Essential role of cytochrome $b d$-related oxidase in cyanide resistance of Pseudomonas pseudoalcaligenes CECT5344. Appl Environ Microbiol 73, 5118-5124.

Raybuck, S. A. (1992). Microbes and microbial enzymes for cyanide degradation. Biodegradation 3, 3-18.

Sambrook, J., Fritsch, E. F. \& Maniatis, T. (1989). Molecular Cloning: a Laboratory Manual, 2nd edn. Cold Spring Harbor, NY: Cold Spring Harbor Laboratory.

Smith, A. F. (1983). Malate dehydrogenase. In Methods of Enzymatic Analysis, vol. III, pp. 163-171. Edited by H. U. Bergmeyer, J. Bergmeyer \& M. Grassl. Weinheim: Verlag Chemie.

Solomonson, L. P. (1981). Cyanide as a metabolic inhibitor. In Cyanide in Biology, pp. 11-28. Edited by B. Vennesland, E. E. Conn, C. J. Knowles, J. Westley \& F. Wissing. New York: Academic Press.

Zagrobelny, M., Bak, S. \& Møller, B. L. (2008). Cyanogenesis in plants and arthropods. Phytochemistry 69, 1457-1468.

Edited by: R. J. M. van Spanning 